\title{
Wrinkles in Parental Time with Children: Work, Family Structure, and Gender
}

\author{
Ronald E. Bulanda, Stephen Lippmann
}

\begin{abstract}
Many factors influence the quantity and quality of parents' time with their children. This review highlights avenues by which work schedules, family structure, and gender individually and collectively relate to parents' allocation of and satisfaction with time with children. Research illustrates that each factor contributes to variability in the effects parents' participation in paid labor has on their time with children. Directions for future research are discussed.
\end{abstract}

Key Words: parents and children, work schedules, family structure, and gender

Ronald Bulanda is Assistant Professor of Sociology, 372 Upham Hall, Miami University, Oxford, Ohio, 45056. Electronic mail may be sent via the internet to bulandre@muohio.edu.

Stephen Lippmann is Assistant Professor of Sociology, 366 Upham Hall, Miami University, Oxford, Ohio, 45056

The two key resources parents provide for their children are money and time (Thomson, Hanson, \& McLanahan, 1994). Yet parental efforts to earn and provide money for their children inevitably require time committed to paid labor. These time commitments to paid labor have the potential to directly take time away from one's family, including spouses and children, and often have the tendency to intrude upon the quality of time spent in the family arena. In a similar manner, one's time committed to paid labor may result in a significant reallocation of time in bdomestic activities for oneself and other family members. In addition, feelings of overwork or stress from paid work have the potential to intrude on the time one does spend with family members. Taken together, it is clear that one's participation in the paid labor force has tremendous implications for the amount, allocation, and quality of time spent in the family arena.

One of the most drastic societal changes over the past few decades has been the increase in women's employment, particularly among mothers. This increase in women's paid labor has elicited much public and academic concern regarding how the employment of mothers affects children (Casper \& Bianchi, 2002). Although a worthwhile concern, it is 
important to acknowledge the full range of potential impact parental employment, especially of mothers, has on parents' time with children. This includes greater attention to how the amount of mothers' and fathers' time with children is influenced, how work schedules influence time allocation, and how parents' feelings about their time commitments may have consequences for the time they do spend in the family arena. In addition, appropriate assessments of parental employment as it relates to time must also make important acknowledgments about family structure, the changing nature of work and work scheduling, and gender. Indeed, maternal employment is likely to have different implications for single mothers than for married mothers; just as emerging workplace technologies and policies may influence a successful balance of work and family time commitments. Moreover, parents' feelings of achieving a successful balance of work and family time are undoubtedly influenced by the gendered nature of work and family roles. Assessments of all of these factors make important contributions to our understanding of how parents' participation in the paid labor force has ripple effects on time allocation and quality within the family, and point to many future directions for future research.

Our goal is to review the literature on families and time. First, we review the literature which assesses how parents, according to labor force status, allocate their time. Next, we review how work schedules, rather than work hours, influence time with children. Next, we review how the demands of work and family make mothers and fathers feel about time, especially that which they spend with their children. We conclude with the identification of several directions for future research regarding the wrinkles in parental time with children formed by the factors of work, family structure, and gender.

\section{Allocation of Parental Time with Children}

Parental time with children is both an important and necessary component of families. The positive influence of parental time with children on child outcomes is well established in the existing literature (Amato \& Rivera, 1999; Cooksey \& Fondell, 1996; Hofferth, 2006). Research has clearly demonstrated the amount of time spent with both mothers and fathers each independently predicts fewer behavioral problems later in childhood (Amato \& Rivera, 1999; Hofferth, 2006). Parental time with children is also positively associated with better academic performance (Cooksey \& Fondell, 1996). Moreover, Hofferth and Sandberg (2001) suggest that time with parents provide opportunities for children's social, cognitive, and emotional development. Additional research provides evidence that loss of parental time with children is associated with a host of negative child outcomes, including dropping out of high school and teen pregnancy (McLanahan \& Sandefur, 1994). 
Although a comprehensive discussion of the measurement strategies used to assess parents' time with children is beyond the scope of this review, it is important to acknowledge that maternal employment has implications for parental time with children, broadly defined. Existing research on parental time with children does reflect some variability in how it is measured, including distinctions between direct parental care and parental accessibility (Hofferth, 2006; McBride, Schoppe, \& Rane, 2002). These distinctions serve as an important acknowledgement that parents spend time with their children in ways that extend beyond direct care. For example, parents may spend time with children in activities such as eating together and performing household tasks (Bryant \& Zick, 1996), or may simply be available to their children (Bulanda \& Majumdar, Forthcoming). Taken together, these measurements of parental time with children reflect that direct involvement with children, as well as parental accessibility, represent potential opportunities to promote child development cognitively and socially. The existing literature demonstrates that each of these measures of parental time to correlate with positive outcomes and well-being in children (Bulanda \& Majumdar, Forthcoming; Hofferth, 2006). In this regard, factors such as maternal employment, which represent a potential threat to actual time of involvement and parental availability, are of tremendous concern.

\section{Influence of Work Schedules on Parental Time with Children}

Parenthood entails the inherent difficulty of providing economic support while simultaneously offering sufficient parental time with children to ensure proper development and child well-being (Bianchi, Robinson, \& Milkie, 2006). And while the inherent work and family dilemma surrounding parenthood remains constant, the context in which this balancing act occurs has changed considerably since 1965. Clearly, one of the most substantial demographic changes in the past four decades has been the increase in market work among women, especially mothers (Bianchi \& Robinson, 1997; Bianchi et al., 2006). This change has resulted in significant interest among scholars regarding its influence on parents' time with children (Bianchi et al., 2006; Hofferth, 2006). Indeed, the increase of mothers in the paid workforce has led many to believe, inside and outside of academia, that the change has resulted in mothers spending less time with their children than in years past (Sayer, Bianchi, and Robinson, 2004). In addition, the higher rates of maternal employment have elicited questions regarding potential differences in how stay at home mothers spend their time with children compared to mothers in the paid labor force (Bianchi \& Robinson, 1997). Researchers have also made linkages between women's employment and an emerging culture of fatherhood, with particular attention to the time and quality of paternal investments in children (Lamb, 2000; Pleck \& Pleck, 1997). 
Indeed, mothers increased market work has had significant implications on family time allocation, especially in terms of parenting (Bianchi \& Raley, 2005).

The primary concern of parenting time as it relates to maternal employment appears to be that mothers must necessarily be spending less time with their children because they are spending more time at work. Many scholars who assess this concern, however, base their inquiries on an assumption that the labor force status of mothers is a proxy for time with children (see Huston \& Aronson, 2005 for a review). This appears to be a faulty assumption, as recent evidence has effectively demonstrated employed mothers often reduce their time investment in other areas, such as housework (Bianchi, 2000), in order to maintain time with their children. This strategic reallocation of time echoes similar findings from two decades ago. Nock and Kingston (1988) had suggested that when parents' work demands during the week took away time they would have spent with children, parents ultimately reduced time spent in activities in which the children were only peripherally involved. By acknowledging working mothers' strategies to protect their time with children, it is apparent that many have overestimated the reduction in time with children as a function of employment status (Bianchi, 2000). In fact, Bianchi and Raley (2005) assert that on average, mothers' overall time with children, approximately 48 hours per week, is consistent with maternal time with children in 1975. Sayer and colleagues (2004) even suggest children of employed mothers in 1998 may have spent more time with their mothers than the average child in 1965, when most mothers did not participate in paid labor. Taken together, it appears working mothers today devote at least as much time to their children as most mothers did before the increase in labor force participation.

Despite this relative consistency in parent-child time among all mothers, a related concern remains about the differences in parental time between employed and non-employed mothers. Existing research illustrates mothers employed throughout their child's childhood spend between $80-90 \%$ the number of hours in childcare activities as mothers who are not employed (see Bianchi, 2000 for a review). Yet it is important to acknowledge that the reduction of time among employed mothers comes almost exclusively from indirect (or secondary) childcare activities (Zick \& Bryant, 1996). Perhaps more important is the explanation for why the gap between working and non-working mothers is smaller than many expect. The answer appears to rest in working mothers reports of fewer hours spent sleeping, in personal care, and in leisure (Bianchi, 2000).

Although such evidence suggests working mothers have been relatively effective in maintaining time with children compared to non- 
working mothers, it is necessary to acknowledge the absence of context in these comparisons. Specifically, maternal employment is certain to effect time allocation in drastically different ways depending on whether the mother is married or single. However, small samples and limited sample designs have made it difficult to provide accurate estimates of how single mothers' time with children has been influenced by maternal employment over the years (Sayer et al., 2004). In turn, much work on maternal employment and parental involvement focuses only on married parent families (Zick, Bryant, \& Osterbacka, 2001). The limited existing research illustrates that single mothers struggle more today to devote time with children than they have in the past, and to provide the amount of time married mothers can afford (Bianchi et al., 2006). In this regard, the limited evidence suggests a strong possibility of a growing inequality in parental time between children of single versus married mothers (Bianchi, 2000; Bianchi et al., 2006). More research will be needed to ascertain factors contributing to this growing inequality.

A factor directly tied to this growing inequality, which has also been the center of many studies as it relates to maternal employment, is the time fathers spend with their children. Indeed, non-resident fathers spend significantly less time with their children compared to resident fathers (Bianchi \& Raley, 2005). Furthermore, the fewer shared domestic responsibilities in a single-mother household places more time commitments on the shoulders of single mothers. In two-parent family structures, there is evidence fathers have increased their role and time commitments to domestic duties, including childcare (Lamb, 2000). Specifically, since maternal employment made its drastic increase in the 1960s, fathers' participation in housework chores has more than doubled (Bianchi \& Raley, 2005). Perhaps more importantly, research shows that from the 1960s through the 1990s, paternal time with children increased both in terms of direct childcare activities and accessibility (Casper \& Bianchi, 2002). Bianchi (2000) asserts the increase in women's market work during this time has facilitated this increase in married fathers' time in childrearing. Yet, despite the increased time demands among today's working mothers and the apparent increased time investment in children among (married) fathers, mothers still invest considerably more time with their children (Sayer et al., 2004).

Although parental time with children is crucial to their cognitive and social development, and working parents may strategically reallocate their time to maximize the amount of time away from work they can spend with their children, several trends and developments in work structuring and scheduling may make this balancing act increasingly difficult. Between 1970 and 2000, the percentage of married couples in which both partners work has risen from $35.9 \%$ to $59.6 \%$. This dramatic change has been accompanied by a steady increase in the number of hours worked per 
week among these dual-earner families (Jacobs \& Gerson, 2004). When these are placed in the context of dramatic and ongoing changes in the structure of work, however, the situation becomes even more complicated. In addition to a net gain in the number of hours working parents spend at work, the rise in nonstandard working arrangements and shift work are presenting new challenges to families and their time allocation strategies.

Nonstandard work arrangements and a resurgence of irregular and unpredictable nonstandard work shifts are hallmarks of the "flexible economy.” Nonstandard work arrangements refer to a rather wide variety of employment relationships that depart in some way or another from those arrangements that characterized "standard" work during much of the $20^{\text {th }}$ century. Standard work included that which was "done full-time, would continue indefinitely, and was performed at the employers place of business under the employer's direction" (Kalleberg, 2000 p. 341). Nonstandard work, therefore, encompasses work that is part-time, temporary, or done under a variety of contracting arrangements. Very often, nonstandard work arrangements carry with them non-standard work schedules that occur during "off hours," or vary by the day, week, month, or year (Presser, 2003a). Together, the rise of the service sector and the globalization of commodity, labor, and financial markets have necessitated not only longer working hours for many, but have also introduced greater variation in the hours of the day that many individuals must spend at work. Those in the less-skilled service sector must provide services on evenings, nights, and weekends while highly skilled professional, executive, and managerial workers must coordinate their activities with others from across the globe. As these work arrangements become increasingly common, they can threaten families' abilities to structure their time in ways that address both work and family responsibilities.

According to Presser (2003a), 40\% of all workers in the U.S. work on non-standard schedules. For those with such work schedules, which are often incompatible with school schedules, those of spouses, or other routine activities of daily life, managing work, family, and other obligations is much more difficult than for those working standard schedules (La Valle, Arthur, Millward, Scott, \& Clayden, 2002). In addition, non-standard schedules are correlated with other negative job characteristics, including low pay, fewer benefits, and reduced opportunities for advancement and mobility (Kalleberg, Reskin, \& Hudson, 2000). Given their association with these negative work and family outcomes, the growth of non-standard work schedules may be introducing a new causal mechanism into the production and reproduction of inequality. This is particularly problematic for single mother families as compared to dual-earner families. According to Presser (2005), dual earner couples who work nonstandard schedules are likely able to split shifts so that one parent is available to children and for household 
responsibilities while the other is at work. Although this situation may not be optimal, it has advantages over that of single mothers whose participation in the labor market necessarily takes them away from the home. Thus, the growth of nonstandard schedules, which are more common among single mothers, may affect them and their children in a particularly negative manner as compared to families dual-earner couples who have more options for allocating parental time. Further, when we consider that African-American, female, and low-wage workers comprise a disproportionately high number of individuals working non-standard schedules, these working arrangements may be further consolidating what are already remarkably durable forms of inequality (Presser, 2003b; Joshi \& Bogen, 2007).

We argue that the key mechanisms underlying the reproduction of inequality across generations are the family-level processes that are set into motion when employed parents involuntarily work non-standard schedules. We define involuntary nonstandard work schedules as those that are scheduled by employers and to which employees must comply as a condition of employment. In addition to the health toll that they can take on workers themselves (Fenwick \& Tausig, 2000; Jamal, 2004), nonstandard and shift work schedules have been found to have negative effects on a variety of family and child outcomes (Barnett, Gareis, and Brennan, 2008; Presser, 2000). Han (2005) found that, overall, mothers' nonstandard work schedules had negative effects on their children's cognitive development. In particular, mothers who work evenings and nights, or at irregular intervals, have little or no access to quality centerbased childcare, and their children may suffer cognitively. Parental nonstandard work schedules also appear to have negative effects on children's social, emotional, and behavioral outcomes. In an analysis of Canadian data, Strazdins, Clements, Korda, Broom and D’Souza (2006) found that children whose parents worked nonstandard hours exhibited poorer emotional well-being, including higher incidence of anxiety and lower levels of self-control. These relationships appear particularly strong in low-income families, where children with mothers who work nonstandard hours exhibit significantly more behavioral problems and fewer positive behaviors in both single-mother and two-parent families (Joshi \& Bogen, 2007).

Perhaps somewhat indicative of the increasing bifurcation of the labor market in terms of education, skills, job quality, and job rewards, other forms of nonstandard work schedules appear to enhance some workers' abilities to manage their work and family lives in an increasingly flexible economy. These arrangements, including flex-time, flex-place, and compressed work weeks, which allow some employees to chose the time, days, and in some cases the location in which their work will occur. These nonstandard schedules, which we characterize as voluntary 
nonstandard schedules, are common among highly skilled workers in some kinds of nonstandard employment relationships, including contract and self-employed workers. Flexible scheduling options are also becoming increasingly common in more traditional employment in organizational contexts. However, these offerings are far from widespread, and appear concentrated among occupations and in organizations where the incumbents are highly educated and whose skills are in high demand (Davis \& Kalleberg, 2006). For these more privileged workers, the ability to adopt nonstandard work hours are part of a wide variety of organizational policies that facilitate work-family balance (Berg, Kalleberg, \& Applebaum, 2003). In fact, flexible scheduling options are positively related to the number of activities mothers and children are able to participate in together, and the ability to work from home increases the amount of time that parents are available to their children (Estes, 2004). Given the positive association between time and availability and positive children's outcomes, it appears that voluntary nonstandard scheduling provides more benefits to children than do more rigid schedules.

Family processes and the quantity and quality of time family members spend with one another are largely responsible for the intergenerational transfers of class and socioeconomic status. However, when family members participate in institutional spheres that exist outside the boundaries of the family, they lose much of their control over their time and the time allocation strategies available to them. The temporal ordering of children's institutions, including childcare, schooling, and extracurricular activities, structures the day-to-day lives of children much as they have for decades. These have been much more impervious to change than those work institutions in which adults spend a significant amount of their time. As the " $24 / 7$ " economy continues to envelop more and more occupations and workplaces, working parents are forced to adapt in order to maintain their livelihoods. However, just as the new economy distributes income, benefits, and prestige in an increasingly polarized manner, it also restructures and redistributes time in ways that the intergenerational transfer of advantage and disadvantage is increasingly likely. For some, the new economy requires nonstandard work hours that reduces the amount of time they are able to spend with their children. For others, though, the new economy offers a new degree of flexibility in work scheduling that allows them to balance work and family obligations to the benefit of their own and their children's lives. Time and individuals' abilities to control are emerging as both causes and consequences of inequality in an increasingly unequal economic regime.

\section{Parental Feelings about Time Spent with Children}


Huston and Aronson (2005) suggest that time alone is not sufficient for proper child development, and that the time spent with children should reflect attentive and sensitive interactions. Although extensive research regarding parents' feeling about time and factors associated with those feelings is lacking (Milkie, Mattingly, Nomaguchi, Bianchi, \& Robinson, 2004), there are some suggestions in the literature that parents may be particularly stressed in the time they do spend with children. While the ideal of family time is generally characterized as overwhelmingly positive, family time is actually often characterized by tension and conflict because parents are tired and stressed from their other life responsibilities (Daly, 2001). This finding is consistent with evidence illustrating that many American families feel their lives are rushed and high tempo, while a growing number of American families feel overworked (Jacobs \& Gerson, 2004). Although a recent qualitative study showed the most commonly expressed concern regarding family time was that there was never enough (Daly, 2001), it appears clear our concern should also center on parents' feelings about the time they do spend with their children.

The apparent irony in the obvious stress of parents to spend sufficient time with their children is the aforementioned research suggesting parents spend as much time, if not more, with their children today than in the 1960s. Indeed, current family ideology is characterized by the belief that more time with children is needed for optimal child development, and that our time with children lags behind families in the past (Bianchi et al., 2006). Today, parents wish they could be fully available to their children when they are home, but instead often feel an urge to force their involvement in family time before bedtime (Daly, 2001). At the same time, Bianchi and colleagues (2006) posit that dual earner couples and single mothers appear most susceptible to "overwork" and are most likely to feel that their family time is being squeezed by their work demands. This is likely to explain why approximately one-half of all resident parents feel they spend too little time with their children (Milkie et al., 2004).

Among parents in dual-earner families, there exists important gender differences in parents' feelings of time strain. First, more fathers than mothers in dual-earner families feel as if they are not spending enough time with their children (Nomaguchi, Milkie, \& Bianchi, 2005). However, this difference is explained by the fact that these fathers generally spend more hours in paid work than their employed spouse. In addition, consistent with a gendered perspective, the differences in role expectations between mothers and fathers appear to result in differences in the psychological consequences of feelings of time strain (Nomaguchi et al., 2005). Specifically, the feeling that they are not spending enough time with their children significantly reduces mothers' subjective assessment of 
their overall life satisfaction. It does not reduce the assessment of life satisfaction for fathers. Given that parenting is more salient to the identity of mothers than fathers (Arendell, 2000), it is not surprising that feelings of time pressure would differ based on the gender of the parent.

This gendered difference in consequences of time pressure is likely to take on added significance for single mothers. Single mothers, who are more likely to work non-standard schedules (Presser, 2005) may be especially vulnerable to time pressure. The non-standard schedules put them at greater risk for poor health (Fenwick \& Tausig, 2000; Jamal, 2004), and the absence of a resident father likely amplifies the motivation to spend even more time with their children. Combined with the idealistic social pressures for mothers to be more actively and visibly involved with their children than they are able (Nomaguchi et al., 2005), it seems the quality of time single mothers spend with their children is at risk.

\section{Conclusion}

It has been posited that time with children represents the resource most strongly related to child outcomes (Hofferth, 2006). This notion is certain to underlie the public and academic concern with the increased rates of maternal employment observed in the last few decades. Although some of the most current literature appears to assuage concerns regarding the time mothers spend with their children, our review suggests that there are many additional concerns regarding parents' time with children. A close examination of familial time allocation, work schedules, and feeling of time conflict reveals an interesting and complex portrait of how employment, family structure, and gender independently and collectively influence the amount, distribution, and quality of parental time with children.

In this review, we acknowledge a need for future research to assess the apparent inequality in time with children in single versus two-parent families. Single mothers feel significantly more strained about their childcare time than married parents, net of their employment status (Bianchi et al., 2006). However, further assessments must be made regarding how the type, schedule, and stability of employment among working single mothers may contribute to their feelings of strain. Prior work shows that single mothers are more likely to work nonstandard schedules and to work weekends compared to married mothers (Presser, 2005). It is possible such work schedule differences contribute to differences in time with children, especially among single mothers with school aged children. Furthermore, it appears necessary to investigate the amount, quality, and consequences of child time spent with relatives (such as grandparents) of employed single mothers. The time with children that single mothers may lose to work activities is easily managed by resident 
fathers, as is the case with employed married mothers. For these reasons, more research is needed to further investigate variations of family time and its consequences in nontraditional family forms (Thomson et al., 1994).

A common limitation of the existing literature is the failure to make linkages between work policies, time with and care of children, and child outcomes (Waldfogel, 2005). While a substantial amount of research exist on family-friendly work policies and their effects on the subjective experience of work-family conflict (see Berg et al., 2003), less is known about how these policies affect the actual allocation of parental time or child behavior and developmental outcomes. Furthermore, in an increasingly flexible economy characterized by a blurring of boundaries between work and family and more fluid organizational structures and scheduling practices, research may also investigate how time itself is a resource that may be distributed in an increasingly unequal manner. Although much is known about job quality in this flexible economy (Kalleberg et al., 2000), research should investigate how "bad" jobs may reduce or alter the quality time available for parents and children to spend together.

Gender may represent the most important factor related to parents' feelings about the time they spend with their children (Milkie et al., 2004). In this sense, the need exists for more research to establish links between parents' time with children and parental gender role characteristics. It is necessary to investigate if and how parents' gender roles and expectations influence the amount and quality of time spent with children. As Bianchi and colleagues (2006) assert, family life today continues to be strongly influenced by gendered beliefs. More specifically, it is clear that the cultural standards for motherhood and men's role in families have an impact not only on work and family time allocation, but also the feelings associated with their time allocation. The disparate implications on life satisfaction for mothers and fathers who feel that they spend insufficient time with children underscore the deeply embedded traditional gender beliefs about parenting. In addition, it highlights a need to assess if and how gender ideologies operate in mothers' and fathers' employment decisions, patterns, and trajectories. For example, it is important to know if parents (especially mothers) who delay childbearing for employment purposes are more likely to report successful work-family balances and satisfaction with time with children.

Ultimately, the existing literature demonstrates that time is an important commodity parents struggle to provide for their children. Work, family structure, and gender represent only three wrinkles of parents' time with children. Additional research is needed to assess these factors, as well as determining optimal levels of parental time for various child 
outcomes.

Michigan Family Review, 13, 5-20, 2009 (C) Michigan Council on Family Relations 


\section{References}

Arendell, T. (2000). Conceiving and investigating motherhood: The decade's scholarship. Journal of Marriage and the Family, 62, 1192-1207.

Amato, P. R., \& Rivera, F. (1999). Paternal involvement and children's behavior problems. Journal of Marriage and Family, 61, 375-384.

Barnett, R. C., Gareis, K. C., and Brennan, R. T. (2008). Wives' shift work schedules and husbands' and wives' well-being in dual earner couples with children. Journal of Family Issues, 29, 396-422.

Berg, P., Kalleberg, A. L., and Applebaum, E. (2003). Balancing work and family: The role of high-commitment environments. Industrial Relations, 42, 168188.

Bianchi, S. M. (2000). Maternal employment and time with children: Dramatic change or surprising continuity? Demography, 37, 401414.

Bianchi, S. M., \& Raley, S. (2005). Time allocation in families. In S. M. Bianchi, L. M. Casper, \& R. B. King (Eds.), Work, family, health, and well-being (pp. 21-42). Mahwah, NJ: Lawrence Erlbaum.

Bianchi, S. M., \& Robinson, J. P. (1997). What did you do today? Children's use of time, family composition, and the acquisition of social capital. Journal of Marriage and Family, 59, 332-344.

Bianchi, S. M., Robinson, J. P., \& Milkie, M. A. (2006). Changing rhythms of American family life. New York: Russell Sage Foundation.

Bryant, W. K., \& Zick, C. D. (1996). An examination of parent-child shared time. Journal of Marriage and Family, 58, 227-237.

Bulanda, R. E., \& Majumdar, D. (Forthcoming). "Perceived parent-child relations and adolescent self-esteem. Journal of Child and Family Studies.

Casper, L. M., \& Bianchi, S. M. (2002). Continuity and change in the American family. Thousand Oaks, CA: Sage Publications. 
Cooksey, E. C., \& Fondell, M. M. (1996). Time with his kids: Effects of family structure on fathers' and children's lives. Journal of Marriage and Family, 58, 693-707.

Daly, K. J. (2001). Deconstructing family time: From ideology to lived experience. Journal of Marriage and Family, 63, 283-294.

Davis, A. E. \& Kalleberg, A. L. (2006). Family-friendly organizations? Work and family

programs in the 1990s. Work and Occupations, 33, 191-223.

Estes, S. B. (2004). How are family-responsive workplace arrangements family friendly?

Employer accommodations, parenting, and children's socioemotional well-being. The Sociological Quarterly, 45, 637-661.

Fenwick, R., \& Tausig, M.. (2000). Scheduling stress: Family and health outcomes of shift

work and schedule control. American Behavioral Scientist, 44, 1179-1198.

Han, W. (2005). Maternal nonstandard work schedules and child cognitive outcomes.

Child Development, 76, 137-154.

Hofferth, S. L. (2006). Residential father family type and child well-being: Investment versus selection. Demography, 43, 53-77.

Hofferth, S. L., \& Sandberg, J. F. (2001). How American children spend their time. Journal of Marriage and Family, 63, 295-308.

Huston, A. C., \& Aronson, S. R. (2005). Mothers' time with infants and time in employment as predictors of mother-child relationships and children's early development. Child Development, 76, 467482.

Jacobs, J. A., \& Gerson, K. (2004). The time divide: Work, family, and gender inequality. Cambridge, MA: Harvard University Press.

Jamal, M. (2004). Burnout, stress and health of employees on nonstandard work schedules:

A study of Canadian workers. Stress and Health, 20, 113-119.

Joshi, P., and Bogen, K. (2007). Nonstandard schedules and young children's behavioral

outcomes among working low-income families. Journal of Marriage and Family, 69, 139-156. 
Kalleberg, A. L. (2000). Nonstandard employment relations: Part-time, temporary, and contract work. Annual Review of Sociology, 26, 341-365.

Kalleberg, A. L., Reskin, B., and Hudson, K. (2000). Bad jobs in America: Standard and nonstandard employment relations and job quality in the United States. American Sociological Review, 65, 256-278.

Lamb, M. E. (2000). The history of research on father involvement: An overview. Marriage \& Family Review, 29, 23-42.

La Valle, I., Arthur, S., Millward, C., Scott, J., \& Clayden, M. (2002). Happy families? Atypical work and its influence on family life. Bristol, UK: Policy Press.

McBride,B. A., Schoppe, S. J., \& Rane, T. R. (2002). Child characteristics, parenting stress, and parental involvement: Fathers versus mothers. Journal of Marriage and Family, 64, 998-1011.

McLanahan, S., \& Sandefur, G. (1994). Growing up with a single parent: What hurts, what helps. Cambridge, MA: Harvard University Press.

Milkie, M. A., Mattingly, M. J., Nomaguchi, K. M., Bianchi, S. M., \& Robinson, J. P. (2004). The time squeeze: Parental statuses and feelings about time with children. Journal of Marriage and Family, 66, 739-761.

Nock, S. L., \& Kingston, P. W. (1988). Time with children: The impact of couples’ work-time commitments. Social Forces, 67, 59-85.

Nomaguchi, K. M., Milkie, M. A., \& Bianchi, S. M. (2005). Time strains and psychological well-being: Do dual-earner mothers and fathers differ? Journal of Family Issues, 26, 756-792.

Pleck, E. H., \& Pleck, J. H. (1997). Fatherhood ideals in the United States: Historical dimensions. In M. E. Lamb (Ed.), The role of the father in child development (pp. 33-48). New York: Wiley.

Presser, H. B. (2000). Nonstandard work schedules and marital instability. Journal of Marriage and the Family, 62, 93-110.

Presser, H. B. (2003a). Working in a 24/7 economy: Challenges for American families. New 
York: Russell Sage Foundation.

Presser, H. B. (2003b). Race-Ethinc and Gender Differences in Nonstandard Work

Shifts. Work and Occupations, 30, 412-439.

Presser, H. B. (2005). Embracing complexity: Work schedules and family life in a $24 / 7$

economy. In S. M. Bianchi, L. M. Casper, R. B. King (Eds.), Work, family, health, and well-being (pp. 43-48). Mahwah, NJ: Lawrence Erlbaum Associates.

Sayer, L. C., Bianchi, S. M ., \& Robinson, J. P. (2004). Are parents investing less in children? Trends in mothers' and fathers' time with children. American Journal of Sociology, 110, 1-43.

Strazdins, L., Clements, M. S., Korda, R. J. Broom, D. H., \& D’Souza, R. M. (2006).

Unsociable work? Nonstandard work schedules, family relationships, and children's well-being. Journal of Marriage and Family, 68, 394-410.j

Thomson, E., Hanson, T. L., \& McLanahan, S. S. (1994). Family structure and child well-being: Economic resources vs. parental behaviors. Social Forces, 73, 221-242.

Waldfogel, J. (2005). Work and family research: A public policy perspective. In S. M. Bianchi, L. M. Casper, R. B. King (Eds.), Work, family, health, and well-being (pp. 231-244). Mahwah, NJ: Lawrence Erlbaum Associates.

Zick, C. D., \& Bryant, W. K. (1996). A new look at parents' time spent in child care: Primary and secondary time use. Social Science Research, 25, 260-280.

Zick, C. D., Bryant, W. K., \& Osterbacka, E. (2001). Mothers' employment, parental involvement, and the implications for intermediate child outcomes. Social Science Research, 30, 25-49. 